\title{
TECHNOLOGY OF PHOSPHORITE AND GLAUCONITE-BASED PHOSPHORITE FERTILIZERS IN KARAKALPAKSTAN
}

\author{
${ }^{1}$ Bauatdinov Sali \\ ${ }^{1}$ Karakalpastan branch of the Academy of \\ Sciences of the Republic of Uzbekistan, \\ Karakalpak Research Institute of Natural \\ Sciences,
}

\author{
${ }^{2}$ Bauatdinov Tashkenbay Salievich \\ ${ }^{2}$ Nukus branch of Tashkent State Agrarian \\ University, \\ Nukus. Uzbekistan
}

\author{
${ }^{3}$ Sayimbetov Alisher \\ ${ }^{3}$ Nukus branch of Tashkent State Agrarian University, \\ Nukus. Uzbekistan
}

\begin{abstract}
ANNOTATION
In order to develop a simplified technology for obtaining phosphorus fertilizers, the process of chemical activation of Khojakul phosphorite flour with mineral fertilizers, which are the main standard fertilizers in agricultural production, was studied. Decomposition of glauconite with nitric, sulfuric and phosphoric acids was carried out. The process of decomposition of glauconite with acid is normal, but after 1.5-3 hours it decreases sharply. The acid has a debilitating effect on glauconite.
\end{abstract}

KEYWORDS: Phosphorite, glauconite, activate, nitric, sulfuric and phosphoric acids, pH, complex compound fertilizer.

\section{INTRODUCTION}

Substantiation of the following scientific solutions for the development of technologies for the production of complex fertilizers in the field of chemical processing of agronomic ores - phosphorite, bentonite, glauconite, vermiculite and other natural minerals in the world today, including determination of optimal conditions of chemical activation of local phosphorite and glauconite with mineral acids or their salts; it is necessary to develop a rational technology for the production of new types of activated complex compound fertilizers based on local agro-ores and mineral salts.

Certain results in the development of mineral fertilizers, including phosphate and calcium oxide ammonium nitrate, ammophos, suprefos-NS, simple and enriched superphosphate, PS-Agro, ammophosphate, potassium chloride, potassium nitrate, ammonium and potassium sulfate on the basis of processing of local raw materials, are achieved.
G. Shobolov [2], D. Gerus [1] noted that bentonite sludge is a cheap natural raw material, has a special significance in world science with its physical and chemical properties. The components of bentonite are mainly small mineral montmorillonite, which determines its physicochemical properties.

Due to the abundance and cheapness of available unconventional mineral raw materials, it is highly effective in replacing some of the deficient minerals in agriculture and being used as a supplement. [3; 4].

The aim of the study is to develop a rational technology for the production of complex fertilizers by chemical activation of Karakalpak lowgrade phosphorite and glauconites with mineral acids and their salts, as well as organic matter.

\section{RESEARCH METHODS}

The composition of Karakalpak glauconite and various types of phosphorites, their physicochemical 
and mechanical properties, physicochemical studies were conducted in experiments.

In order to develop a simplified technology for obtaining phosphorus fertilizers, the process of chemical activation of Khojakul phosphorite flour with mineral fertilizers, which are the main standard fertilizers in agricultural production, was studied. The process of activation of phosphate raw materials is mainly the process of activation of phosphorite flour to determine the effectiveness of mineral fertilizers, taking into account the soil moisture, its duration ammonium nitrate $(34.4 \% \mathrm{~N})$, ammonium sulfate $(21.0 \% \mathrm{~N}) 2$ $20 \%$, ammonium chloride $(26.0 \% \mathrm{~N})$, urea $(46.0 \%$ $\mathrm{N})$, potassium chloride $\left(60.0 \% \mathrm{~K}_{2} \mathrm{O}\right)$ and urea nitrate $(33.97 \% \mathrm{~N})$ mineral fertilizers (MF) and phosphate flour (FF), as well as sulfuric acid, sulfuric acid solution of ammonium sulfate and nitric acid and nitric acid solution of ammonium nitrate, solutions are prepared by vigorous mixing of the components for 30 minutes. After the interaction of the components, the suspensions were dried in a thermostat at $105^{\circ} \mathrm{C}$ and various forms of nitrogen and phosphorus in the product composition were analyzed.

\section{RESEARCH RESULTS}

Studies have shown that a number of mineral salts are effective for activating phosphorites: urea nitrate $>$ ammonium sulfate $>$ mono-ammonium phosphate $>$ ammonium nitrate $>$ ammonium chloride $>$ potassium chloride $>$ urea.

A simplified technological system for obtaining slow-acting complex fertilizers at minimum humidity in the presence of a solution that binds a mixture of phosphorite flour and mineral fertilizers used in the auger mixer was proposed. Agrochemical tests have shown that the obtained fertilizers are not inferior to existing fertilizers in terms of their effectiveness.

It is necessary to obtain complex mixed fertilizers on the basis of Karakalpak agro-ores. Karakalpak agronomic ores - low-grade slag phosphorites, glauconite sands, bentonites, etc. can be an environmentally friendly and effective unconventional fertilizer.

Studies of glauconites have shown that they contain essential components such as potassium, aluminum, iron, magnesium, calcium, phosphorus, and more than 15-20 microelements. Currently, the soils of Karakalpakstan are in great need of macro and micro elements, so including them with glauconite sand in the soil (glauconite - 35-40\%, quartz - 33-55\%, feldspar - 6.4-6.9\%, phosphorite $0.7-0.9 \%$, iron hydroxide $-3.5-4.0 \%$, gypsum - 0.4 $0.5 \%$ micas - 0.2-0.3; calcite - $0.1-0.2 \%$ ) will increase the productivity and quality of agricultural crops.
The processes of decomposition of glauconite with nitric, sulfuric and phosphoric acids were studied in order to search for the possibility of converting the nutrient components of glauconite into plant-assimilated form. The process of decomposition of glauconite with acid is normal, but after 1.5-3 hours it decreases sharply. The acid has a debilitating effect on glauconite. However, no $\mathrm{SiO}_{2}$ precipitation is observed during the decomposition of Kirantau glauconite with nitric acid, as the conversion of $\mathrm{SiO}_{2}$ to the colloidal state is minimized. In this regard, nitric acid acts as a coagulator and dehydrator on amorphous $\mathrm{SiO}_{2}$. Because the role of acids in the interaction with glauconite leads to the formation of $\mathrm{SiO}_{2}$ membranes of various natures, which have a weakening effect of the acid on glauconite, forming a dense vitreous shell of $\mathrm{SiO}_{2}$, which makes it difficult for the acid to enter the mineral, as well as reaction products explained by reverse diffusion.

Acid-activated glauconite (glauconite: acid $=1: 0.5)$ to obtain a complex compound fertilizer was neutralized with Khojakul phosphorite flour (FF) in a ratio of phosphorite: glauconite $=1:(0.25-1)$ and granulated in the presence of an ammonium sulfate bonded solution. Depending on the ratio of components, complex compound fertilizers have the following composition (weight.\%): 1) in the activation of glauconite with nitric acid - in the form of nitrogen and calcium nitrate - 0.82-2.15; $\mathrm{P}_{2} \mathrm{O}_{5}-$ $14.44-9.59 ; 32.20-34.52 \%$ of it in the form of assimilation; $\mathrm{K}_{2} \mathrm{O}$ - 0.42-1.13; $\mathrm{CaO}$ - 26.70-17.74; $\mathrm{N}_{2} \mathrm{O}-1.5-1.6$ and micro elements; 2 ) in the activation of sulfuric acid - in the form of nitrogen ammonium sulfate - $0.01 ; \mathrm{P}_{2} \mathrm{O}_{5 \text { gen. }}$ - 14,44-9,09; $\mathrm{P}_{2} \mathrm{O}_{5 \text { assim. }}$ - 2.62$3.28 ; \mathrm{K}_{2} \mathrm{O}-0.42-1.05 ; \mathrm{CaO}-26.70-16.74 ; \mathrm{N}_{2} \mathrm{O}-1.5-$ 1.6 and micro elements; 3 ) in the activation of phosphoric acid - in the form of nitrogen ammonium sulfate - 0.01; $\mathrm{P}_{2} \mathrm{O}_{5 \text { gen. }}$ - 15.78-13.73; $\mathrm{P}_{2} \mathrm{O}_{5 \text { assim. }}$ 5.99-6.93; $\mathrm{K}_{2} \mathrm{O}-0.42-1.18 ; \mathrm{CaO}-14.83-18.54 ; \mathrm{N}_{2} \mathrm{O}$ - 3.55-1.86 and micro elements.

In addition, the composition and properties of complex fertilizers obtained by mixing Kirantau mechanically activated glauconite sand with a ratio of 1: (0.25-1) with the content of ammophos sludge $(\mathrm{pH}=3.5-4.2)$ and (weight.\%): $\mathrm{SiO}_{2}-67.92, \mathrm{Al}_{2} \mathrm{O}_{3}-$ 9.43, $\mathrm{Fe}_{2} \mathrm{O}_{3}+\mathrm{FeO}$-7.99, $\mathrm{CaO}-0.73, \mathrm{MgO}-0.43$, $\mathrm{Na}_{2} \mathrm{O}-2.80, \mathrm{~K}_{2} \mathrm{O}-3.20, \mathrm{CO}_{3}-7.78, \mathrm{P}_{2} \mathrm{O}_{5}-0.78$, kjy6.,14 and micro elements ( $\mathrm{Si}, \mathrm{Mn}, \mathrm{B}, \mathrm{Cu}, \mathrm{Co}, \mathrm{Mo}$, etc.) were studied. An increase in the $\mathrm{pH}$ of fertilizers was found due to the interaction of free acid of sludge with the components of glauconite.

Glauconitized ammophos fertilizer glaucophos is not hygroscopic in terms of physical and mechanical properties and meets the requirements of agriculture. The results of the study were tested on an enlarged experimental device of the Institute of General and Inorganic Chemistry. The results of agrochemical tests conducted at the Research Institute of Cotton Breeding, Seed 
Production and Agrotechnology and the Karakalpak Agricultural Research Institute show that "Glaukofos" has high agrochemical efficiency. Phosphorite component for the development of fertilizer technology, which contains large amounts of glauconite and has good agrochemical and commercial properties - the composition and properties of granulated complex compound fertilizer in the presence of a binder solution consisting of ground ammophos or a mixture of Karakalpakstan slag phosphorite and glauconite were studied. Saturated solutions of ammonium sulfate or ammonium sulfate nitrate or ammonium phosphate in the amount of $1-15 \%$ (in dry matter) relative to the mass of the ready fertilizer were used as a binder solution.

Phosphorus component in complex compound fertilizers: glauconite by weight ratio 1 : 0.25-1. In granulation and agricultural use, the process of activation of phosphorite and glauconite nutrient components takes place, that is, they become assimilated for plants.

\section{CONCLUSION}

With an increase in acidity from 20 to $60 \%$ of stoichiometry, the rate of decomposition of phosphate raw materials increases. Decomposition of nitric acid at a rate of $40 \%$ and above leads to a deterioration of its commercial properties due to an increase in the amount of groscopic salt calcium nitrate in the product. To improve its commercial properties, the decomposition of phosphorite was carried out in a nitric acid solution of ammonium nitrate obtained by dissolving ammonium nitrate in nitric acid, with a decomposition coefficient of phosphate raw material 1.22 times higher than that of nitric acid.

Conditions for composting of cattle and poultry manure together with phosphorite were determined. At the same time, as the duration of composting of organic fertilizers with phosphorite flour increases, the rate of conversion of the nonabsorbable form of $\mathrm{P}_{2} \mathrm{O}_{5}$ to the assimilated form increases. When the weight ratio of manure to phosphorite is 1:0.12, $\mathrm{P}_{2} \mathrm{O}_{5 \text { assim. is obtained during }}$ composting for one month. The relative rate was $26.5 \%$ and after 3 months $-48.6 \%$. After three months of composting, poultry manure-based compost contains 1.3-1.4 times more $\mathrm{P}_{2} \mathrm{O}_{5 \text { assim. }}$.

\section{REFERENCES}

1. Gerus V. Bentonite in the market of capitalist countries // Bulletin of foreign commercial information. MVT USSR, No. 58 (3713).Moscow: Mir, 1972. -28 p.

2. Shobolov P.S. Placement of bentonite deposits of new montmorillonite clays // Turkmen Polymechanical Institute. - Ashgabat, 1968, no. 5, 36-41 p.
3. Vakanjats Branimiz. New and unconventional non-metallic raw materials in Yugoslavia, 1988. 25-32 p.

4. http://ibm..nic.in/w ritereaddata/files 